\title{
Menumbuhkan Budaya Literasi Bahasa Inggris Melalui Extensive Reading di Taman Baca Masyarakat (TBM) Kota Tasikmalaya
}

\author{
Setyo Wati \\ Universitas Perjuangan Tasikmalaya \\ Email: Anasetyowati33@gmail.com
}

\begin{abstract}
This community service program is motivated by the low level of literacy skills of the Indonesian people. This fact proves that the literacy value of Indonesian people reading is still very low. According to TBM West Java data in 2017, the Tasikmalaya region in the districts and cities has more than ten scattered community reading parks, but most have not been maximally utilized by the surrounding community, especially for the availability of English books. Seeing the above phenomenon, it is necessary to have a solution in the community. This community service program offers a language literacy program using the Extensive Reading method as an effort to foster community literacy. The main reason for this literacy program is that literacy is the right of everyone and is the basis for learning throughout time. This program combines foreign language learning with community literacy programs. This activity involved TBM managers and children as participants in the activity. The Extensive Reading method is used in community service programs to foster community literacy. The results of these community service activities include a literacy program that introduces extensive reading methods in improving integrated and effective English language skills to help equalize education through integrated reading services in Nagarasari, Tasikmalaya city.
\end{abstract}

Keywords: Literacy, English, Extensive Reading

\section{Pendahuluan}

Budaya literasi dalam masyarakat Indonesia dapat dikatakan rendah. Berdasarkan data Perpustakaan Nasional Tahun 2017 mengenai frekuensi membaca orang Indonesia rata-rata hanya tiga sampai empat kali per minggu, sedangkan jumlah buku yang dibaca rata-rata hanya lima hingga sembilan buku per tahun 1 . Rendahnya minat baca masyarakat mengakibatkan rendahnya literasi masyarakat, dimana peningkatan kapasitas Sumber Daya Manusia (SDM) sangat erat kaitannya dengan kemampuan literasi. 
Literasi telah menjadi istilah yang populer dewasa ini. Pemerintah Indonesia pun gencar melakukan gerakan literasi karena pemerintah Indonesia menyadari bahwa tingkat literasi masyarakat Indonesia sangat memprihatinkan ketika dibandingkan dengan negara- negara tetangga yang lain. Secara sederhana, literasi adalah kemampuan membaca dan menulis (keberaksaraan) $^{2}$. Literasi memiliki makna dasar yang merupakan pintu utama bagi pengembangan literasi secara lebih luas. Pemahaman akan sesuatu informasi secara tepat akan diperoleh dari proses membaca dan memahami isi bacaan yang didapat dari suatu sumber bacaan yang ada. Semakin banyak membaca, semakin banyak pula informasi yang didapat. Dengan kata lain, semakin banyak membaca, semakin banyak pula pemahaman suatu data yang dibutuhkan di masyarakat sehingga seseorang yang dikatakan literat ketika paham akan apa yang dia baca.

Pilar budaya literasi erat kaitannya dengan budaya membaca. Membaca menjadi kunci untuk mengetahui informasi dan mencerdaskan kehidupan bangsa. Dalam proses pembelajaran bahasa, sebelum seseorang itu dapat menulis, dia memulai dari membaca. Secara berkaitan, seseorang yang pandai merangkai kata dalam tulisan bararti dia pun telah memperkaya khasanah ilmunya melalui membaca.

Hal ini tentu suatu fenomena yang miris, ketika masyarakat Indonesia memiliki tingkat literasi yang sangat rendah, padahal penguasaan literasi dalam segala aspek kehidupan merupakan tulang punggung kemajuan peradaban suatu bangsa sehingga pembangunan budaya literasi pada masyarakat Indonesia dirasa sangat penting. Budaya literasi pada masyarakat diupayakan sebagai suatu kebiasaan berfikir yang diikuti dengan proses membaca serta menulis sehingga pada akhirnya apa yang dilakukan dalam seluruh proses kegiatan tersebut akan menciptakan karya yang bermanfaat bagi masyarakat tersebut. 
Oleh karena itu kegiatan yang dilakukan ini sejalan dengan cita- cita bangsa Indonesia untuk menjadi negara maju. Program literasi melalui "Penguasaan Bahasa Inggris melalui Metode Extensive Reading" ini sebagai upaya menumbuhkan budaya literasi masyarakat ini akan menjadi solusi yang bermanfaat di lingkungan masyarakat dalam mendorong peningkatan kualitas hidup, kreatifitas, kemandirian, dan daya saing di masa yang akan datang. Selain itu, program ini merupakan program literasi yang berkelanjutan bagi masyarakat sekitar dengan pemanfaatan program literasi guna memajukan kesejahteraan masyarakat dan mencerdaskan kehidupan masyarakat. Tujuan yang hendak dicapai dalam kegiatan ini adalah memperkenalkan metode extensive reading dalam peningkatan kemampuan bahasa Inggris yang terpadu dan efektif dan membantu dalam rangka pemerataan pendidikan melalui layanan baca yang terpadu.

\section{Metode}

Metode pelaksanaan pengabdian ini menggunakan metode Extensive Reading. Untuk mengukur ketercapaian tujuan, kegiatan ini terlebih dahulu diawali dengan ini pre-test; sebagai data yang mendiskripsikan kemampuan awal para peserta, 8 pertemuan program kegiatan, dan kemudian post-test; sebagai evaluasi dari proses kegiatan yang telah ditempuh. Dalam kegiatan ini, ketua pelaksana mengajak 1 anggota dari dosen dan 2 anggota dari mahasiswa untuk membantu jalannya program ini. Mahasiswa yang dilibatkan adalah mahasiswa yang telah mengikuti pembelajaran bahasa Inggris minimal 1 semester di perkuliahan serta memiliki kemampuan bahasa Inggris yang cukup baik, baik dalam bahasa lisan maupun tulisan. Hal ini bertujuan melatih para mahasiswa dalam mengaplikasikan ilmu yang telah mereka dapatkan selama kuliah dan melatih mereka dalam melakukan penelitian di masyarakat. Meskipun keterlibatan mereka tidak terlalu banyak di kegiatan ini, tetapi diharapkan hal tersebut mampu menjadi titik awal konstribusi mahasiswa Universitas Perjuangan Tasikmalaya di masyarakat. 
Kegiatan tersebut berlangsung selama 3 jam pada setiap pertemuannya yang dipandu oleh fasilitator dari tim pengabdian masyarakat. Adapun dalam program pengabdian masyarakat ini terbagi menjadi 3 bagian, yaitu pertama pada kegiatan pembukaan ini, ketua pelaksana dibantu dengan dua mahasiswa melakukan pengecekan kemampuan bahasa Inggris untuk mengetahui kemampuan dasar Bahasa Inggris peserta dengan menggunakan vocabulary card yang berisi gambar. Pelaksana membutuhkan data tersebut untuk menyesuaikan bahan bacaan di level manakah yang diperlukan untuk program ini. Kedua, pada tahap pertemuan berikutnya adalah kegiatan program Extensive Reading yang dilakukan secara intensif. Kegiatan ini dilengkapi dengan penjelasan dari pelaksana yang dikemas dengan fun games agar program literasi bisa terlaksana dengan maksimal. Ketiga, kegiatan penutup, sekaligus pemerolehan hasil evaluasi kegiatan. Para peserta diminta untuk menjawab pertanyaan- pertanyaan bahasa Inggris sederhana pada level dasar yang meliputi vocabulary dan English culture. Hasil yang diperoleh merefleksikan kontribusi yang baik atas kegiatan yang terselenggara terhadap peningkatan kemampuan menyimak dan teknik penyelesaian soal mereka. Selain itu dalam kegiatan penutupan ini, dalam kegiatan ini juga dihibahkan buku- buku untuk peningkatan literasi masyarakat setempat.

\section{Hasil dan Diskusi}

Kegiatan pengabdian yang dilaksanakan dengan tatap muka dan program literasi bahasa Inggris dengan metode Extensive Reading ini berjalan dengan baik dan lancar sebagaimana yang diharapkan. Pelaksanaan kegiatan Pengabdian ini dilakukan oleh dua orang dosen Universitas Perjuangan Tasikmalaya jurusan Pendidikan Bahasa Inggris dengan dibantu dua mahasiswa Universitas Perjuanga. Hasil dari pengabdian ini untuk menggerakkan minat baaca bahasa Inggris anak- anak dan menambah sumber media belajar sendiri, serta menambah literatur belajar bahasa asing 
bagi anak- anak.

Tabel 1. Jadwal Realisasi Kegiatan

\begin{tabular}{|l|l|l|l|l|l|l|l|l|l|l|l|l|l|}
\hline No & Jenis Kegiatan & 1 & 2 & 3 & 4 & 5 & 6 & 7 & 8 & 9 & 10 & 11 & 12 \\
\hline 1 & $\begin{array}{l}\text { Koordinasi } \\
\text { dengan TBM Gali } \\
\text { Nagari. }\end{array}$ & & & & & & & & & & & & \\
\hline 2 & $\begin{array}{l}\text { Penyiapan alat } \\
\text { dan bahan yang } \\
\text { dibutuhkan. }\end{array}$ & & & & & & & & & & & & \\
\hline
\end{tabular}

Sumber: Pelaksanaan Kegiatan, 2018

Extensive Reasing dalam program Bahasa Inggris dikolaborasikan dengan games untuk membuat anak-anak senang dan bersemangat dalam mempelajari bahasa untuk membantu siswa dalam melibatkan emosional siswa dengan subjek belajar. Selain itu, program ini menggunakan teknik membaca yang melibatkan minat baca buku yang mereka sukai.

Pada tahap pertama ini, kegiatan yang dilakukan adalah dengan melakukan pengecekan kemampuan dasar bahasa Inggris kepada pengunjung TBM yang datang dimana pengunjung yang datang adalah anakanak berusia antara umur 4 tahun sampai 13 tahun. Hal ini dilakukan untuk mengetahui kemampuan awal para peserta. Kegiatan awal ini dilakukan dengan tebak gambar dan artinya dalam bahasa Inggris. Konsep yang dilakukan adalah dengan metode games agar anak- anak terhibur dan sekaligus bisa belajar. 


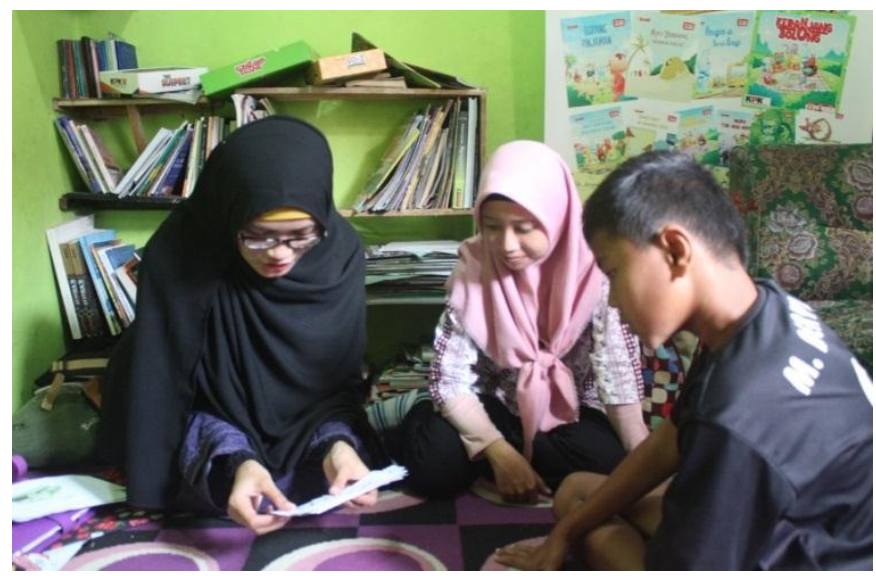

\section{Gambar 1. Pengecekan kemampuan awal para peserta kegiatan} (Sumber: Dokumentasi Kegiatan, 2018)

Kegiatan kedua dalam kegiatan ini adalah fasilitator membuka dengan kegiatan motivational upgrading. Motivational upgrading dilakukan terlebih dahulu untuk meningkatkan motivasi dari pengunjung yang masih tergolong anak- anak dalam mengikuti program ini. Pada tahap ini, fasilitator memperkenalkan buku- buku bercerita bergambar yang menggunakan 2 bahasa, yaitu bahasa Inggris dan bahasa Indonesia.

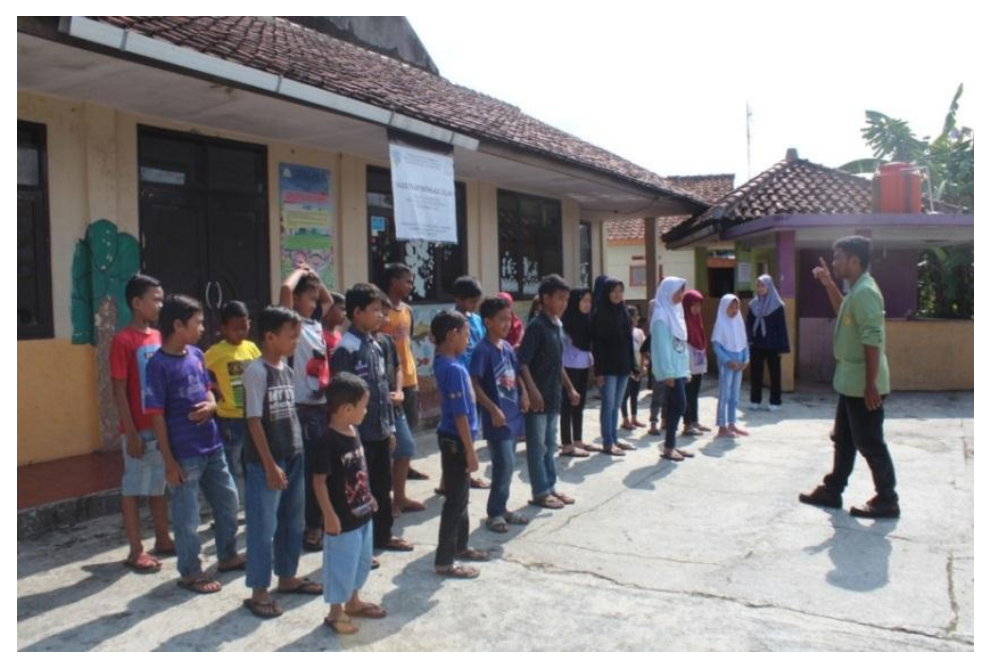

Gambar 2. Motivational Upgrading

(Sumber: Dokumentasi Kegiatan, 2018) 
Tahap selanjutnya adalah sebelum para pengunjung TBM membaca buku, fasilitator memperkenalkan English vocabularies dalam bentuk gambar dengan menggunakan learning games. Hal ini bertujuan untuk penumbuhan minat baca masyarakat terhadap literasi bahasa Inggris. Anak- anak yang tergolong menyukai hal yang berwarna, maka fasilitator menyediakan bukubuku berwarna dan bergambar yang memiliki cerita sehari- hari yang menarik. Dari sekian banyak buku, anak- anak diminta untuk memilih sendiri buku yang paling disukai kemudian mereka membacanya. Dengan didampingi fasilitator, anak- anak diberi kesempatan bertanya kepada fasilitator jika ada pertanyaan. Di sesi ini pun fasilitator membacakan cerita pada salah satu buku, mengingat dari sekian banyak pengunjung, ada beberapa anak yang masih tergolong masih balita sehingga belum bisa membaca.

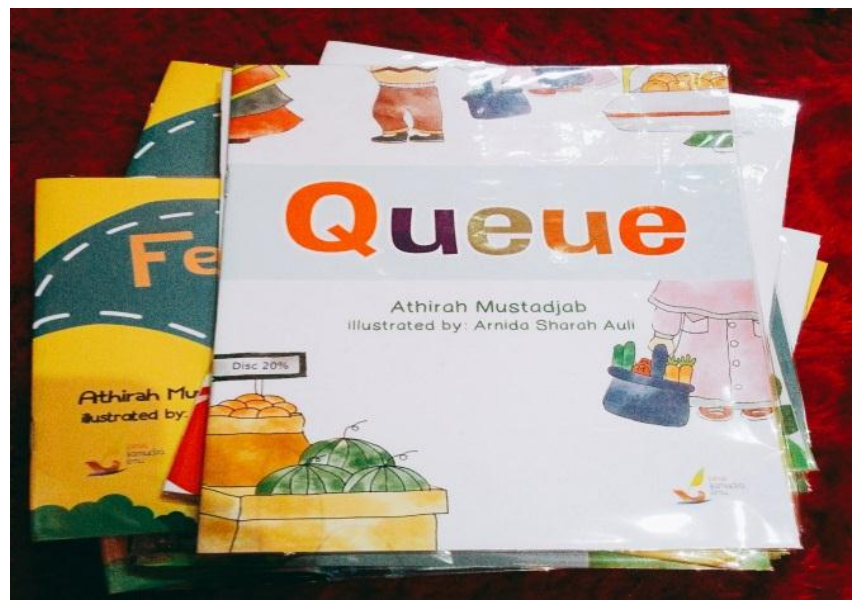

\section{Gambar 3. Buku yang Digunakan dalam Program} (Sumber: Dokumentasi Kegiatan, 2018)

Tahap selanjutnya, fasilitator melakukan review kosakata bahasa Inggris yang telah dipelajari pertemuan sebelumnya. Kendala yang dihadapi pada pertemuan sekarang adalah adanya penurunan pengunjung TBM dan perubahan pengunjung yang datang sehingga fasilitator harus mengulang materi kosakata yang lalu agar pengunjung tidak kesulitan dalam membaca 
buku yang disediakan dan memahaminya. Pengurangan jumlah pengunjung tersebut adalah dari 33 orang anak menjadi 20 orang anak. Buku bacaan yang dipilih pada pertemuan sekarang masih seperti yang sebelumnya yaitu menonjolkan unsur pewarnaan gambar yang colourful dengan topik cerita sehari- hari.

Bagi anak- anak yang paling semangat dalam mengikuti kegiatan diberikan hadiah agar mereka semakin semangat lagi dalam mengikuti kegiatan. Setelah kegiatan penumbuhan dan pengenalan metode Extensive Reading, tahap selanjutnya adalah fasilitator mengajak pengunjung dalam gerakan literasi dengan metode Extensive Reading kepada aggota keluarga mereka agar para pengunjung bisa menularkan semangat membaca kepada anggota keluarga mereka.

Kegiatan terakhir dari projek ini adalah kegiatan pembelajaran mengenai pengenalan budaya bahasa target (bahasa Inggris) yang disampaikan menggunakan metode tanya-jawab dan simulasi di taman baca masyarakat kota Tasikmalaya. Media yang digunakan yaitu flashcards. Flashcards ini dijadikan alat untuk menarik perhatian peserta sehingga mereka tertarik untuk mengetahui kalimat dan gambar yang ada di dalamnya. Gambar dan kalimat dalam flashcards memiliki nilai budaya dari bahasa target yang dijelaskan oleh fasilitator.

Kegiatan terakhir diadakan evaluasi untuk merefleksikan kontribusi yang baik atas kegiatan yang terselenggara terhadap peningkatan kemampuan menyimak dan teknik penyelesaian soal mereka. Selain itu dalam kegiatan penutupan ini juga dihibahkan buku- buku untuk peningkatan literasi masyarakat setempat. 


\section{Simpulan}

Program literasi bahasa Inggris dengan metode Extensive Reading di Taman Baca Masyarakat Gali Nagari ini diharapkan mampu mensosialisasikan taman baca kepada masyarakat yang tinggal di Nagarasari, kota Tasikmalaya sehingga masyarakat mendapatkan pemerataan pendidikan melalui program literasi yang menyenangkan sebagai sarana belajar masyarakat. Dengan adanya kegiatan ini pula diharapkan dapat menyiapkan masyarakat agar memiliki dasar bahasa Inggris yang bisa menjadi bekal menghadapi era globalisasi. Selain itu, kegiatan ini merupakan wadah bagi kalangan akdemisi untuk berinteraksi secara langsung kepada masyarakat sehingga ke depannya akan semakin membuka peluang terjadinya kerjasama guna mencari solusi bagi permasalahan pendidikan bahasa yang dijumpai..

\section{Daftar Referensi}

CNN Indonesia. Minat Baca Masyarakat Indonesia, diakses 23.08/2018. https://www.cnnindonesia.com/gaya-hidup/20180326160959-282285982/minat-baca-masyarakat-indonesia-masih-rendah, 208.

Erman Syamsudin. Membangun Budaya Literasi. Jurnal AKRAB Volume 7 Edisi 1 (2016) hal. 4-5 